\title{
Lance-Adams syndrome: A special case of a mother
}

\author{
Gaurav Bhaskar Nigam, Sachin Suresh Babu', C. Sudhir Peter ${ }^{2}$, C. Shobhna Peter ${ }^{2}$
}

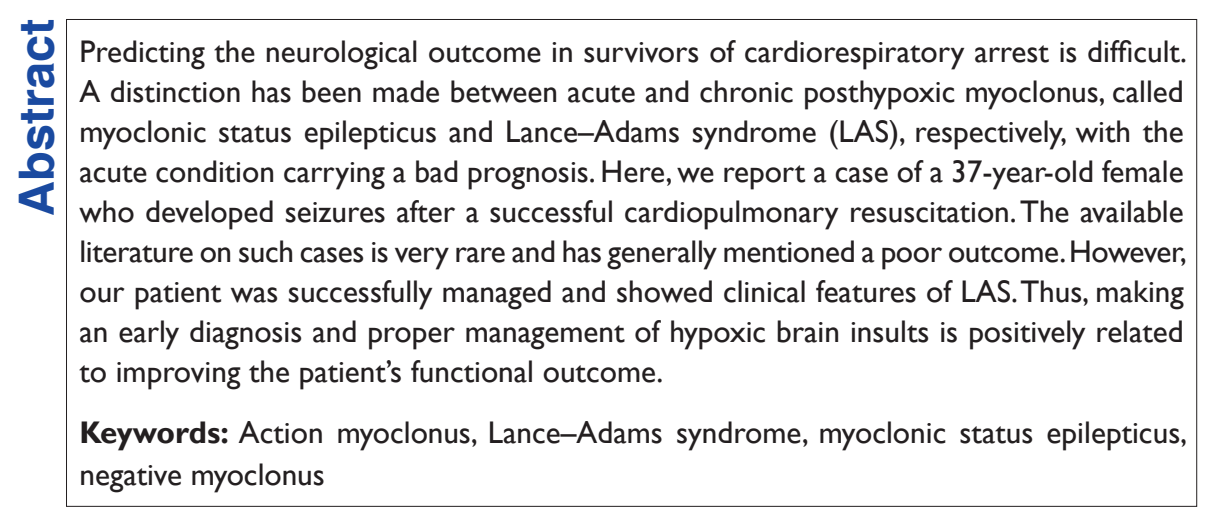

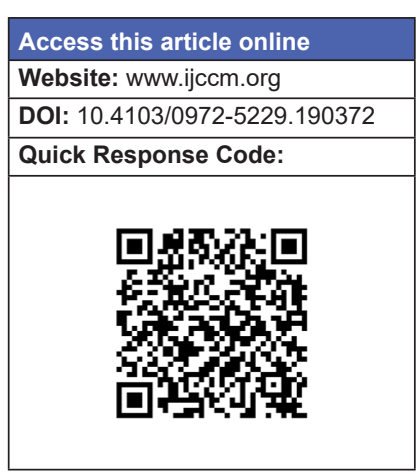

\section{Introduction}

Improvement in the knowledge and training of health-care personnel in giving appropriate resuscitation therapy has increased the number of patients who survive a cardiorespiratory arrest. With this has come into light cases of neurological complications in the survivors, such as posthypoxic myoclonus (PHM), characterized by uncontrolled myoclonic jerks following cardiac arrest. Two types of PHM can occur in patients with hypoxic injury of the brain: acute and chronic. Acute PHM, termed posthypoxic myoclonic status epilepticus (MSE), occurs soon after a hypoxic insult in patients who are deeply comatose and implies a poor prognosis. The chronic type of PHM, also known as Lance-Adams syndrome (LAS), is characterized by action myoclonus beginning within days to weeks after cardiopulmonary resuscitation (CPR) and persists in patients who have recovered consciousness after CPR. ${ }^{[1,2]}$ Here, we present a patient who was diagnosed as having LAS post-CPR and review the available literature on this rare entity.

From:

Departments of Medicine and ${ }^{1}$ Neurology, St. Stephen's Hospital, New Delhi,

${ }^{2}$ Metropolis Labs, Alappuzha, Kerala, India

\section{Correspondence:}

Dr. Gaurav Bhaskar Nigam, Flat No. 166 Mall Apartment, Mall Road,

Near GTB Metro Station, New Delhi - 110 054, India.

E-mail: drgauravbnigam@gmail.com

\section{Case Report}

Here, we present the case of a 37-year-old lady, a known case of rheumatic heart disease with a bad obstetric history admitted at 32 weeks of gestation for a precious pregnancy in view of difficulty in breathing. The initial evaluation and baseline investigations were found to be normal, and the patient was being managed conservatively. During the evening rounds, the patient complained of severe breathlessness and developed cyanosis with a drop in saturation to $40 \%$. The patient became unconscious with a pulse rate of $40 / \mathrm{min}$ and was immediately intubated, put on mechanical ventilation. An urgent cesarean section was done to deliver the babies.

About $3 \mathrm{~h}$ after this event, the patient developed tonic-clonic movements, which were managed with bolus doses of midazolam. The seizures could not be controlled, and loading doses of phenytoin, valproate, and levetiracetam were added, and the seizures

This is an open access article distributed under the terms of the Creative Commons Attribution-NonCommercial-ShareAlike 3.0 License, which allows others to remix, tweak, and build upon the work non-commercially, as long as the author is credited and the new creations are licensed under the identical terms.

For reprints contact: reprints@medknow.com

How to cite this article: Nigam GB, Babu SS, Peter CS, Peter CS. Lance-Adams syndrome: A special case of a mother. Indian J Crit Care Med 2016;20:548-50. 
controlled. However, the patient continued having intermittent jerky movements, and midazolam infusion was started. The seizure activity was controlled to some degree, but thiopentone infusion was required to attain burst suppression on electroencephalogram (EEG). The antiepileptic doses of phenytoin, levetiracetam, and valproate were brought to their maximum, and then, thiopentone infusion was tapered off gradually; but then, the patient started having intermittent myoclonic jerks for which topiramate $300 \mathrm{mg} /$ day, zonisamide $300 \mathrm{mg} /$ day, piracetam $12 \mathrm{~g} /$ day, clobazam $30 \mathrm{mg} /$ day and clonazepam $2 \mathrm{mg} /$ day were tried sequentially to achieve full control. Infrequent jerks continued which did not have an EEG correlate, and the drugs were tapered off one by one over a period of 2 months. The patient was maintained on zonisamide, clonazepam, and piracetam at the time of discharge. When the patient was seen on follow-up, the patient had characteristic negative myoclonic (NM) jerks with action myoclonus suggestive of LAS.

\section{Discussion}

Myoclonus is a movement disorder, which presents itself with sudden, brief, shock-like jerks. Most myoclonic jerks are due to a brief burst of muscular activity, resulting in positive myoclonus. When jerks result from brief cessation of ongoing muscular activity, they are called NM. ${ }^{[3]}$ Myoclonus can be classified in a number of ways, physiological classification being the most practical, since the presumed source of myoclonus (cortical, subcortical, spinal, or peripheral) guides the most effective therapy. Electrophysiological tests are very helpful in determining whether myoclonus is cortical, subcortical, or spinal.

An alternate way of classifying myoclonus is based on the activity during which it occurs, the one occurring during action being called action myoclonus. In a given patient, more than one form of myoclonus may occur. For instance, in LAS, cortical myoclonus may coexist with brainstem myoclonus. ${ }^{[4]}$ LAS was originally described as inattention or action myoclonus in 1960s seen in four patients who developed myoclonic jerks within a few days following an episode of anoxia. ${ }^{[1]}$ This is in contrast to the generalized multifocal myoclonus seen in acute settings called MSE. MSE predicts death or permanent vegetative state in more than $90 \%$ of survivors ${ }^{[5]}$ and maybe confused with chronic PHM of LAS, having a favorable prognosis, in patients with persistent coma receiving sedation.

A brief distinction on the features of the two entities is listed in Table 1.
Table I: Clinical features of Myoclonic status and LAS

\begin{tabular}{|c|c|c|}
\hline & Myoclonic status & Lance-Adams syndrome \\
\hline Consciousness & Comatose & Aware, caution on sedation \\
\hline Time interval & $\begin{array}{l}\text { Within I2-24 h, stops } \\
\text { after } 24 \mathrm{~h}\end{array}$ & Late onset may become chronic \\
\hline Myoclonus & Generalized, multifocal & Usually inattention myoclonus \\
\hline Prognosis & Extremely poor & $\begin{array}{l}\text { Normally preserved intellect, } \pm \\
\text { chronic myoclonus }\end{array}$ \\
\hline Pathophysiology & $\begin{array}{l}\text { Ischemic brain injury } \\
\text { with neuronal necrosis }\end{array}$ & $\begin{array}{l}\text { Hypoxic brain injury without } \\
\text { reversible infarction }\end{array}$ \\
\hline
\end{tabular}

LAS occurs in patients after they have regained consciousness days to weeks after CPR. The myoclonic jerks are specifically triggered by action, startle, stimulus such as touch, tracheal suctioning, and loud handclaps, as was seen in our patient, and they usually disappear with relaxation of the body and limbs or with sleep. The myoclonus in LAS has no consistent correlation with EEG abnormalities.

Diagnostic imaging tests such as computed tomography (CT) or magnetic resonance imaging of the brain are not helpful to make a diagnosis of LAS. Recently, neuroimaging studies have shown the anatomical and pathophysiological basis of PHM and include: (i) Patients of LAS with increased glucose metabolism in the pontine tegmentum, mesencephalon, and ventrolateral thalamus. ${ }^{[6]}$ (ii) In two patients with LAS, brain single-photon emission CT showed mild hypoperfusion in the left temporal lobe in one patient, and brain positron emission tomography showed a mild bilateral decrease of glucose metabolism in the frontal lobes in the other. ${ }^{[7]}$

LAS has diverse clinical, electrophysiological, and neurochemical abnormalities, and the neurotransmitters related to LAS are known to be serotonin and gamma-aminobutyric acid (GABA). The loss of serotonin within the inferior olive nucleus has been thought to play a certain role ${ }^{[8]}$ and GABA may interact with the serotonin system to suppress PHM. ${ }^{[9]}$

The treatment of LAShas beenlimited, and a combination of medications based on the neurotransmitters has been reported. Frucht and Fahn reviewed more than 100 patients with LAS, and they found that clonazepam, valproate, and piracetam were effective in treating approximately $50 \%$ of the cases. ${ }^{[10]}$ Levetiracetam, zonisamide, clonazepam, and valproate may be recommended as first-line agents of choice. ${ }^{[11]}$

\section{Conclusion}

Postcardiac arrest myoclonus does not have a universally poor prognosis. Knowledge on differentiating between MSE and LAS can help predict the correct prognosis for 
the patient. Increasing the awareness of critical care doctors about this rare entity with appropriate therapy can save many lives. Our case presented with an overlap of the MSE and LAS, and proper care helped achieve a positive result.

\section{Financial support and sponsorship}

Nil.

\section{Conflicts of interest}

There are no conflicts of interest.

\section{References}

1. Lance JW, Adams RD. The syndrome of intention or action myoclonus as a sequel to hypoxic encephalopathy. Brain 1963;86:111-36.

2. English WA, Giffin NJ, Nolan JP. Myoclonus after cardiac arrest: Pitfalls in diagnosis and prognosis. Anaesthesia 2009;64:908-11.

3. Shibasaki H, Hallett M. Electrophysiological studies of myoclonus. Muscle Nerve 2005;31:157-74.

4. Borg M. Symptomatic myoclonus. Neurophysiol Clin 2006;36:309-18.
5. Wijdicks EF, Hijdra A, Young GB, Bassetti CL, Wiebe S; Quality Standards Subcommittee of the American Academy of Neurology. Practice parameter: Prediction of outcome in comatose sur after cardiopulmonary resuscitation (an evidence-based review): Report of the Quality Standards Subcommittee of the American Academy of Neurology. Neurology 2006;67:203-10.

6. Frucht SJ, Trost M, Ma Y, Eidelberg D. The metabolic topography of posthypoxic myoclonus. Neurology 2004;62:1879-81.

7. Zhang YX, Liu JR, Jiang B, Liu HQ, Ding MP, Song SJ, et al. Lance-Adams syndrome: A report of two cases. J Zhejiang Univ Sci B 2007;8:715-20.

8. Welsh JP, Placantonakis DG, Warsetsky SI, Marquez RG, Bernstein L, Aicher SA. The serotonin hypothesis of myoclonus from the perspective of neuronal rhythmicity. Adv Neurol 2002;89:307-29.

9. Matsumoto RR, Truong DD, Nguyen KD, Dang AT, Hoang TT, Vo PQ, et al. Involvement of GABA(A) receptors in myoclonus. Mov Disord 2000;15 Suppl 1:47-52.

10. Frucht S, Fahn S. The clinical spectrum of posthypoxic myoclonus. Mov Disord 2000;15 Suppl 1:2-7.

11. Polesin A, Stern M. Post-anoxic myoclonus: A case presentation and review of management in the rehabilitation setting. Brain Inj 2006;20:213-7. 